\title{
MAU ALUNO, BOA ALUNA? COMO AS PROFESSORAS AVALIAM MENINOS E MENINAS
}

\author{
MARILIA PINTO DE CARVALHO
}

\begin{abstract}
Resumo: Baseado em pesquisa qualitałiva numa escola pública de ensino fundamental de São Paulo, o artigo discute os critérios de avaliação escolar das professoras, apontando em que medida suas opiniões sobre masculinidade e feminilidade interferiam em seus julgamentos e o que era mais valorizado no comportamento de meninas e meninos. Conclui pela urgência de promover essa reflexão no campo edúcacional, pois, se já eram marcantes em sistemas de avaliação mais formalizados, com testes, atribuição de notas e organização da escola em séries, as hierarquias de gênero parecem tornar-se mais poderosas nas chamadas avaliações de processo, em curso na maioria das escolas brasileiras, a partir do sistema de ciclos.

Palavras-chave: ensino fundamental, avaliação, relaçōes de gênero, fracasso escolar
\end{abstract}

As estatísticas nacionais, embora precárias no que se refere à desagregação por sexo, não deixam dúvidas quanto à diferença de desempenho escolar entre meninos e meninas em todo o ensino fundamental e médio. Pode-se tomar os dados sobre evasão e repetência ou as informações sobre defasagem entre série cursada e idade da criança: qualquer dessas cifras indica que os meninos teriam maiores dificuldades escolares.

Antes, porém, de nos indagarmos sobre possíveis motivos para essa situação, é preciso atentar ao fato de que o conteúdo dessas estatísticas tem uma relação indireta com a efetiva aprendizagem. Por exemplo, os dados mais recentes apontam grande diminuição nas taxas de repetência, mas isso resulta principalmente de políticas educacionais de melhoria do fluxo, que conduziram à aprovação automática de alunos e, portanto, não reflete necessariamente uma real melhoria no acesso ao conhecimento.

Alunos e alunas estão permanecendo mais tempo nas escolas, repetindo menos de ano e afastando-se menos da atividade escolar, o que, sem dúvida, são avanços. Contudo, a pressão exercida sobre os professores para que aprovem o maior número possível de alunos, nas séries em que ainda existe a reprovação (finais de ciclo), e a falta

' Este artigo apresenta resultados parciais de uma pesquisa financiada pela Fapesp e que integra o projeto "A gestão da violência e da diversidade na escola", do Programa de Cooperação Internacional Brasil-França (CAPES-COFECUB).

ANO $9554 \quad 2^{\circ}$ SEMESTRE 
de condições efetivas para um trabalho de recuperação paralela da aprendizagem, para o bom funcionamento das classes de aceleração e mesmo para um trabalho pedagógico de qualidade nas classes regulares, levam-nos a duvidar dos efeitos dessas medidas, ligadas aos ciclos e à aprovação automática, sobre a efetiva apropriação dos conhecimentos por alunos e alunas, isto é, sobre a democratização do acesso ao saber. ${ }^{2}$

O que estou querendo afirmar é que as estatísticas de desempenho escolar têm alguma relação com a aprendizagem dos alunos, porém essa relação é intermediada: pelas políticas educacionais - que podem, por exemplo, levar a fortes pressões pela diminuição drástica do número de reprovados, ou mesmo de indicados para atividades de recuperação; pelo relacionamento entre professores, professoras, alunos e alunas, sempre perpassado por um conjunto de desigualdades sociais como aquelas decorrentes de relações raciais, de classe e de gênero; assim como pelos critérios de avaliação adotados explícita ou implicitamente, mais ou menos conscientemente pelos encarregados de avaliar e atribuir conceitos ou notas aos alunos.

Portanto, é às políticas educacionais e a esse emaranhado de interações e de critérios de avaliação que devemos estar atentos, ao buscar as formas de produção do fracasso escolar mais acentuado entre os meninos em nossas escolas. Não se trata, nesse caso, de discutir se meninos ou meninas são mais aptos à aprendizagem, mais rápidos, mais inteligentes ou mais afeitos a alguma aprendizagem específica - questões sem dúvida também relevantes. Aqui, o foco estará sobre os processos que têm conduzido um maior número de meninos do que meninas a obter notas baixas ou conceitos negativos, e a ser indicados para atividades de recuperação; o que pode - ou não - estar relacionado a sua efetiva aprendizagem e a eventuais dificuldades diante do conhecimento.

Do ponto de vista das relações de gênero - em suas complexas inter-relações com as desigualdades de classe e raça - parece que múltiplas dimensões da vida escolar e da infância articulam-se na produção desse quadro de maiores índices de fracasso escolar entre pessoas do sexo masculino: as relações de crianças ou jovens entre si, suas culturas e formas de sociabilidade, permeadas por diferenças e desigualdades de gênero; as interações entre professores, professoras, alunos e alunas, marcadas pela presença majoritária de mulheres no magistério, particularmente no início da escolarização; as expectativas e formas de educação diferenciadas estabelecidas pelas famílias para seus filhos e filhas; e, finalmente, as opiniões dos professores e professoras sobre as relações de gênero em geral e seus critérios de avaliação de alunos e alunas.

Neste artigo, apenas o último aspecto mencionado estará em relevo, pois, apesar de nos parecer um dos pontos de estrangulamento das atuais políticas educacionais, é um elemento pouco discutido nas pesquisas da área. Mesmo a literatura internacional trata apenas esparsamente desse tema, se pode ser tomada como significativa a amostra a que tive acesso. A questão do fraco desempenho escolar dos meninos tem recebido ampla atenção, especialmente nos países de língua inglesa (e secundariamente também na França), tanto na mídia quanto na pesquisa acadêmica e entre os formuladores de políticas educacionais, porém, emerge a partir dos resultados de testes padronizados, 0 que torna menos relevante o estudo das falas, opiniões e avaliações dos professores. ${ }^{3}$

As informações aqui utilizadas foram coletadas numa investigação de caráter qualitativo junto às turmas de quarta série numa escola pública de ensino fundamental do

\footnotetext{
${ }^{2}$ CARVALHO, 2000

${ }^{3}$ Foram-me particularmente úteis na análise desse tema específico: ARNOT, 1999; GILBERT, Rob e GILBERT, Pam, 1998; MAC AN GHAILL, 1995; WARRINGTON e YOUNGER, 2000, p. 493-508; WALKERDINE, 1995.
} 
município de São Paulo, ao longo do ano de 2000. Foram gravadas entrevistas semiestruturadas com as duas professoras de classe e a orientadora educacional; e realizadas observações nas salas de aula regulares, em suas atividades de recuperação, nas reuniões pedagógicas e nos conselhos de classe realizados no segundo semestre de 2000 que diziam respeito às quartas séries. Além disso, os alunos e alunas dessas classes que participaram da recuperação paralela foram entrevistados e participaram de uma atividade gravada. ${ }^{4}$

Procuramos perceber o que as professoras consideravam fundamental avaliar e como o faziam; em que medida suas opiniões sobre masculinidade e feminilidade interferiam nesses julgamentos e o que era mais valorizado no comportamento tanto de meninas quanto de meninos. Nem sempre o que apreendemos foram preconceitos ou estereótipos explícitos, mas sutis interpenetrações entre opiniões estereotipadas e julgamentos profissionais bem fundamentados, cujos efeitos se ampliavam na medida da falta de critérios de avaliação objetivos e coletivamente explicitados pela equipe escolar. Assim, iniciamos a discussão apresentando um quadro geral da avaliação e seus critérios naquela Unidade Escolar. Embora o olhar das professoras seja nosso objeto central, em alguns momentos suas falas serão entremeadas às opinióes de crianças entrevistadas, na tentativa de iluminar esse outro ângulo da relação pedagógica. Esse contraponto não está mais desenvolvido tanto por razões de espaço quanto pelo caráter inicial do trabalho empírico junto aos alunos e alunas. Também lançamos mão, por vezes, de informações obtidas nas observações diretas das salas de aula e das reuniões pedagógicas.

\section{"Eu me sinto muito perdida com esses conceitos"}

A escola estudada atende a 670 alunos do ensino fundamental e médio, em dois períodos de funcionamento: das $7 \mathrm{~h} 30$ às 12 horas, estudam os jovens de sexta série do fundamental até o terceiro ano do médio; e das 13 às 17 horas, as crianças de primeira a quinta série do ensino fundamental. São 40 professores e professoras, todos com curso superior e quase todos com jornada de 40 horas semanais, com um máximo de 20 horas em sala de aula e as demais voltadas a reuniões, preparação de aulas e aperfeiçoamento profissional. A equipe técnica conta com duas orientadoras educacionais e uma coordenadora pedagógica, além de diretor e vice-diretor. E os serviços de apoio operacional e secretaria dispõem de quatro inspetores de alunos, um técnico de laboratório, uma bibliotecária, um técnico de manutenção, um porteiro, uma secretária e cinco auxiliares administrativos, além de 12 funcionários de limpeza. O prédio é grande, arejado e espaçoso, embora apresente problemas de conservação que chegam a comprometer o uso de determinados espaços.

Como se pode depreender, apesar de pertencer à rede pública estadual, essa escola apresenta características próprias e condições de funcionamento particularmente adequadas. Todas as classes contam com 30 alunos e mesclam crianças provenientes de setores populares, médios e médios intelectualizados, abrangendo um grupo bastante heterogêneo em termos sócio-econômicos, étnico-raciais e culturais, particularmente se comparada à homogeneidade que em geral se encontra tanto nas escolas públicas de periferia, quanto nas escolas particulares de elite, numa cidade como São Paulo.

Aqui teremos em foco especialmente as duas classes de quarta série, num total de 60 alunos, atendidos por duas professoras, que dividiam entre si as disciplinas: Célia

\footnotetext{
${ }^{4}$ Agradeço a Patrícia Martins Penna a colaboração no trabalho empírico. Todos os nomes de pessoas e instituições são fictícios.
}

ANO 9556 20 SEMESTRE 
responsabilizando-se por Matemática e Ciências, e Laís, que ensinava Português, História e Geografia. Ambas as professoras têm curso superior de Pedagogia, e Célia cursava, em 2000, mestrado em Educação, na área de Ensino de Ciências. Eram jovens, com 26 e 27 anos, tinham pequena experiência profissional e estavam naquela escola há dois anos, no caso de Laís, e há três, no de Célia.

A escola em questão adotou, a partir de 1999, o sistema de avaliação por conceitos "PS" (plenamente satisfatório), "S" (satisfatório) e "NS" (não satisfatório) - com dois ciclos no ensino fundamental (de primeira a quarta e de quinta a oitava séries). Existe um sistema de recuperação paralela ao longo de todo o ano, chamado de "oficinas de reforço", que são oferecidas pela própria professora de classe nas primeiras séries ou da matéria, nas séries finais. No caso das séries iniciais, que estudamos, essas oficinas ocorriam pela manhã, uma vez por semana, com duração de duas horas e meia. Célia e Laís atendiam a grupos diferentes de alunos das duas classes de quarta série, conforme tivessem dificuldades em português ou matemática (ou em ambas as disciplinas). De acordo com elas, eram as professoras que indicavam os alunos para o reforço. Alguns permaneciam durante todo $o$ ano, enquanto outros, que apresentavam dificuldades pontuais, eram atendidos por períodos variáveis e depois dispensados. Elas indicavam tanto alunos classificados com conceito "NS", quanto alunos que obtinham "S", mas "estavam cambaleando", na expressão de Célia.

Como professoras de quarta série - encerramento do primeiro ciclo-, elas deveriam decidir, ao final do ano letivo, se algum aluno seria reprovado, e comentaram em entrevista suas dificuldades diante desse quadro. Embora Laís revelasse mais dúvidas quanto ao uso dos conceitos, ambas pareciam ter problemas, especialmente com os alunos intermediários, aqueles que deveriam ser classificados como " $\mathrm{S}$ ":

Eu me sinto muito perdida com esses três conceitos. [...] Porque para mim, Laís, não satisfatório é uma pessoa que não faz, se recusa a fazer. Não quer fazer, não se envolve em hipótese alguma, não entregou, não fez. [...] Para mim, o NS é nulo. A partir do momento que você se propôs a ler um texto, se propôs a tentar responder alguma coisa, pelo menos essa sua atitude já é satisfatória. Mas aí, é satisfatório para esse tamanho [gesto de pequenez]. É muito complicado (Laís).

Na verdade, três conceitos é muito pouco para a gente estar avaliando. São muitas crianças, eles são muito diferentes. Três conceitos não é nada. E às vezes você tem um $\mathrm{S}$, que é uma criança muito boa mas que ainda não está Plenamente Satisfatória. E você tem muitas vezes um $S$ que é aquela criança que saiu do NS e que está entrando. A distância é muito grande. [...] Acho que às vezes a gente é muito... muito injusta com algumas crianças até (Célia).

Quanto à reprovação ao final do ano, Laís mostrou-se particularmente insatisfeita, indicando a dificuldade em avaliar os alunos sem avaliar simultaneamente a própria escola:

o que a quinta série espera dos nossos alunos? O que uma quinta série dessa escola espera desses alunos? A partir daí, a quinta série - a escola - está estruturada para saber o que quer, o que espera, para estabelecer certos limites de quem pode freqüentá-la ou não? Eu acho que não está, porque se a escola inteira... se eu sinto falta de uma linha [de trabalho comum] de primeira a quarta [séries], como é que eu posso decidir se eles estão aptos ou não pra quinta? Eu acho que para mim é um conflito muito grande, inclusive eu não concordo com a questão da reprovação, ah, em momento algum [ri] (Laís, ênfase na fala).

O discurso de Laís e o de Célia tinham muitos pontos em comum, com certas diferenças de ênfase. Ambas afirmavam avaliar os alunos a partir de uma multiplicidade de instrumentos (trabalhos individuais sem consulta, do tipo "prova", trabalhos em grupo

ESTUDOS FEMINISTAS $557 \quad 2 / 2001$ 
feitos em classe e em casa, participação nas aulas, lições de casa etc.); e diziam que procuravam levar em conta tanto o desempenho propriamente dito, quanto o que chamavam de "compromisso do aluno" ou "relação da criança com o cotidiano da escola". Nas palavras de Célia:

Eu acho que entra toda essa coisa do compromisso, a responsabilidade, eu acho que tá tudo envolvido. [...] Eu acho que tá tudo muito misturado, é muito difícil, acho, a gente separar essas coisas. Muitas vezes, talvez, a falta de compromisso da criança influencie bastante no fato dela não conseguir alcançar aqueles objetivos. Mas a gente tem outras crianças que são supercompromissadas e que mesmo assim não conseguem alcançar minimamente os objetivos (Célia, ênfase na fala).

Perguntadas sobre as razões das dificuldades escolares de algumas crianças naquela escola, contudo, Laís e Célia percorreram caminhos bastante diversos em suas explicações. Laís remeteu-se imediatamente aos problemas internos de funcionamento da escola, afirmando que, sem dúvida, os problemas de aprendizagem e reprovação ali eram menores que na maioria das escolas públicas, eram "mais amenizados", mas que os profissionais ainda enfrentavam dificuldades no sentido de articular uma linha pedagógica comum:

A proposta pedagógica ainda é muito isolada, inclusive é uma exigência muito grande dos pais aqui da escola, que existisse continuidade. Eu me sinto como se fosse assim, metaforicamente, uma linha que emendasse as pérolas, sabe? Assim, as pérolas estão meio espalhadas, que às vezes dá a sensação de estar remando contra a maré, de estar cada um correndo para um lado. Em dados momentos o grupo de primeira a quarta se sente assim e coloca essa dificuldade nessa questão da linha (Laís).

Coerentemente, ao discutir a avaliação, Laís, como vimos, retomou as dificuldades de um trabalho coletivo em continuidade, criticando a falta de critérios para avaliar e para reter alunos na quarta série.

Já Célia respondeu à mesma pergunta sobre as dificuldades de desempenho escolar entre alunos de primeira a quarta séries, remetendo a questão às famílias:

Eu acho assim, não há um motivo principal. Eu acho que tem um conjunto de motivos em volta. Uma coisa que eu sinto muita falta - eu estou falando por mim - o que eu sinto muita falta é o apoio da família. A gente tem muitos casos de alunos em que você chama a família, a família lava as mãos. [...] Então eu acho que essa parceria família-escola é muito importante. E muitas vezes a gente não encontra esse respaldo na família (Célia, ênfase na fala).

Na literatura pedagógica, a discussão sobre as razões do fracasso escolar é antiga e profícua e tem freqüentemente oscilado entre os dois pólos expressos nas falas de Laís e Célia: a culpabilização das famílias e a busca de causas intraescolares. A complexificação do debate, contudo, tem indicado que múltiplas dimensões interferem nesse processo e que é preciso levar em conta tanto as condições sócio-econômicas e culturais de origem da criança, quanto as condições de funcionamento das escolas, o preparo dos professores, os critérios de avaliação etc. ${ }^{5}$ O que essa literatura não tem abordado com a devida profundidade é o fato de que, no grupo daqueles que fracassam na escola, ou diante dos quais a escola fracassa em ensinar, os meninos são em número maior que as meninas. Irmãos e irmãs de uma mesma família, "estruturada" ou não, estudando numa mesma escola "bem organizada" ou não, podem apresentar resultados escolares totalmente diversos. ${ }^{6}$

${ }^{5}$ AQUINO, 1992; ARROYO, 2000; PATTO, 1990.

${ }^{6}$ Três exceções na literatura nacional são: ABRAMOWICZ, 1995; SILVA, 1999, p. 207-225; BERNARDES, 1989. 
Na escola estudada, entre os 52 alunos de primeira a quarta série atendidos em algum momento de 2000 nas oficinas de reforço, 20 eram meninas (38,5\%) enquanto 32 eram do sexo masculino (61,5\%). Isso significa que $21,5 \%$ de todos os alunos haviam passado pelas oficinas, sendo $15,8 \%$ do total de meninas, diante de $27,8 \%$ de todos os meninos. Em particular nas duas classes de quarta série, dos 60 alunos, 13 estiveram nas oficinas de reforço ao longo do ano, sendo nove meninos e quatro meninas. Considerandose que eram ao todo 35 crianças do sexo feminino e 25 do sexo masculino, temos que $11 \%$ de todas as meninas da quarta série foram indicadas em algum momento para as oficinas, enquanto o mesmo ocorreu com $36 \%$ dos meninos. Como explicar essa diferença? Tentemos ir um pouco mais a fundo nos critérios de avaliação de nossas professoras e nas suas idéias sobre as relações sociais de gênero.

\section{"É uma excelente aluna, mas..."}

Alguns pesquisadores têm relatado que, num primeiro contato, professores e professoras afirmam desconhecer qualquer diferença de desempenho escolar entre meninos e meninas, como se essa simples constatação fosse expressão de preconceito e tratamento desigual. Cármen Silva e colaboradores, por exemplo, descrevem a reação dos professores e professoras que entrevistaram em Pelotas como sendo de "bastante surpresa e, logo após, de dúvida". ${ }^{7}$ Este foi o caso também dos educadores e educadoras franceses ouvidos por Claude Zaïdman, ${ }^{8}$ que, diante das questões da pesquisadora sobre as diferenças de comportamento e desempenho escolar entre os sexos, afirmavam a própria imparcialidade ao ensinar e uma total igualdade entre seus alunos e alunas. Seu apelo principal era à noção de "neutralidade", fundamentada menos na recusa das diferenças entre os sexos do que no receio de cair em afirmações sexistas, e recorrendo a uma ética profissional laica, muito enraizada na escola francesa, que considera os alunos como indivíduos despojados de qualquer característica social, até mesmo sua origem étnica ou o sexo.

Ao contrário, nas escolas em que temos investigado esse tema, ${ }^{9}$ ouvimos quase sempre uma concordância quanto às diferenças de comportamento e desempenho entre meninos e meninas. Não há espanto, surpresa ou recusa de nossa questão central - estudar as causas do fracasso escolar mais acentuado entre meninos. Na escola aqui referida, ao apresentar a proposta da pesquisa à equipe de orientação escolar e em reunião com o conjunto de professores, também não encontramos qualquer dificuldade no reconhecimento da diferença de desempenho escolar entre os sexos, questão identificada como merecedora de reflexão.

Quando se tratava da diferença sócio-econômica, entretanto, era o silêncio que prevalecia. Atendendo a crianças de origens sociais bastante diversificadas, os educadores da escola estudada tendiam, como os franceses entrevistados por Zaidman, a afirmar a neutralidade de suas ações e avaliações, insistindo na heterogeneidade das turmas, na ausência de testes seletivos para ingresso na primeira série e enfatizando a imparcialidade dos critérios de avaliação. Contudo, num levantamento inicial através de questionário respondido pelas famílias, pudemos constatar que, enquanto $50 \%$ dos alunos de primeira

\footnotetext{
7 SILVA et al., 1999, p. 214.

${ }^{8}$ ZAIDMAN, 1996, p. 83-84.

${ }^{9}$ Além da escola em questão, uma investigação de menor monta foi desenvolvida em 1999, numa escola pública da periferia da região metropolitana de São Paulo (CARVALHO, 2000).
} 
a quarta séries vinham de famílias com renda familiar superior a dez salários mínimos, entre os alunos em recuperação esse índice caía para $28,2 \%$ (11 alunos em 41 ). ${ }^{10}$

No caso das duas professoras de quarta série, era nítida a diferença de percepção quanto ao desempenho de meninos e meninas: enquanto Laís respondeu prontamente à questão se havia alguma característica comum no grupo de alunos com dificuldades escolares, dizendo que "o número de meninos é maior e vai se acentuando [de uma série para outra]"; Célia voltou a mencionar as "famílias desinteressadas", reproduzindo um discurso bastante difundido na cultura escolar brasileira. Essa diferença de percepção pode estar articulada a uma visão mais crítica das relações de gênero no discurso de Laís, que chegou a freqüentar disciplina a respeito durante seu curso superior. Ela mostra estar atenta à questão, particularmente diante das pesquisadoras, ao comentar sua classe de terceira série, já em 2001: "Esse ano, toda segunda-feira, eu lembro de você: tenho sete no reforço e os sete são meninos". Ou ao falar sobre uma escola de educação infantil na qual trabalhou:

Uma coisa curiosa lá é que a dona da escola, a diretora da escola, faz questão de presença masculina, ela exige professor na escola. Não existiu um momento em que a escola não tivesse pelo menos dois professores, pelo menos um deles todos os dias. Ela faz questão absoluta disso. E se um professor... se tem uma criança que precisa trocar fralda, ele vai trocar fralda. Nesse ponto eu acho muito legal (Laís).

Contudo, Célia, que não mencionou o sexo como característica marcante dos alunos indicados para atividades de recuperação, tendia a mencionar mais meninas que meninos como exemplo de bons alunos.Diante da pergunta "Me fala o que seria um bom aluno de uma de suas classes, um exemplo", ela respondeu:

Olha, deixa eu ver, uma boa aluna... vou falar alguns nomes de bons alunos aqui da quarta II [consulta lista de alunos]: Alice, que é uma boa aluna; Ana Paula, Cláudio é um bom aluno. Marieta é uma excelente aluna (Célia).

Vale a pena chamar a atenção para a passagem feita pela professora do gênero masculino, no qual foi formulada a pergunta, para o feminino, ao pensar em exemplos. Diante do fato de ela ter consultado a lista de alunos que estava sobre a mesa, poderíamos pensar que sua escolha estivesse influenciada pela ordem nessa lista, pois havia mais nomes femininos com as primeiras letras $(A \mathrm{e} C$ ). Entretanto, ela pulou rapidamente para a letra "m", após mencionar Cláudio." E, no conjunto da entrevista, doze meninas e nove meninos foram mencionados como "bons" ou "excelentes" alunos. Também cabe destacar que, em outro momento da pesquisa, foram classificadas por Célia como brancas 16 dessas 21 crianças citadas por ela espontaneamente como "bons alunos". As exceções foram um menino classificado como "pardo", uma menina e um menino como "orientais" e um menino e uma menina "pretos". ${ }^{12}$

O sentido subjetivo dessa "branquidade" pode ser avaliado, entre outras coisas, pelo fato de que três dos "bons alunos" vistos como brancos por Célia foram classificados como "pardos" por Laís (duas meninas e um menino). Na classificação das crianças

\footnotetext{
${ }^{10}$ Talvez a percepção dessas desigualdades se expressasse nas falas das educadoras através de seus comentários sobre as famílias dos alunos (famílias "desestruturadas", "que colaboram" ou que "Iavam as mãos" etc.), mas este é um tema que não será desenvolvido aqui.

${ }^{11}$ Apesar de os nomes dos alunos serem fictícios, foi mantida a primeira letra desses nomes.

${ }^{12} \mathrm{Em}$ entrevistas realizadas em abril de 2001, cada uma das professoras foi solicitada, separadamente, a classificar os alunos das duas turmas de quarta série de acordo com os critérios de raça/cor do IBGE ("branco", "preto", "pardo", "oriental" ou "índio").
}

ANO $9 \quad 560 \quad 20$ SEMESTRE 
indicadas para atividades de reforço ou que tiveram problemas disciplinares formalizados (advertência e/ou suspensão) em 2000, não houve qualquer discrepância entre as opiniões das professoras. Além disso, 12 dessas 21 crianças pertenciam a famílias com renda mensal acima de dez salários mínimos e somente sete a famílias com renda inferior a essa (não temos informação sobre duas delas).

Assim, parece que não apenas se reconhece a existência de problemas escolares maiores entre os meninos, como também a imagem de "bom aluno" estaria mais associada às meninas brancas (e orientais), talvez a um certo perfil de feminilidade.

Pois, de acordo com as falas dessas professoras, o "bom aluno" seria "quem participa; quem consegue ter um elo legal com o grupo; quem se envolve com a escola" (Laís). E muitas meninas são descritas como boas alunas, mas sem essas características, o que ofuscaria suas qualidades:

a Marieta é uma excelente aluna, mas ela raramente questiona, ela é muito certinha, sabe aquela criança muito certinha, muito CDF, até demais? [...] Alice, que entrou esse ano na escola, é daquelas também assim CDF, aquela que não pisca na aula... não questiona, nada, nada... [...] Ela é muito tímida, ela tem um problema na fala também, então a gente percebe que ela evita, fala pouco e tal. Mas é uma boa aluna (Célia, ênfase minha).

Assim, quem efetivamente se encaixava no perfil de "excelente aluno", participativo, crítico e ao mesmo tempo cumpridor das tarefas, rápido na aprendizagem e organizado, era um pequeno número de meninas "questionadoras" e, especialmente, um grupo significativo de meninos, quase todos vistos como brancos ou brancas pelas professoras. Sobre um desses meninos, Célia disse: "Aquela criança compenetrada, equilibrada, todo certinho, mas de um jeito legal" (ênfase minha). Assim, enquanto os meninos bons alunos eram descritos como "bem humorado", "uma liderança positiva", "engraçado", "curioso", "danado fora da sala de aula", muitas meninas eram apontadas como boas alunas, apesar de serem caladas, obedientes, não questionadoras.

Este tipo de postura ambígua das professoras e professores diante das meninas tem sido encontrado em inúmeras pesquisas e descrito em termos muito semelhantes em diferentes países, sendo interpretado a partir de variadas grades teóricas. No Brasil a pesquisa de Silva e colaboradores ${ }^{13}$ fala de meninas percebidas como responsáveis, organizadas, estudiosas, sossegadas, caprichosas, atentas, "mas menos inteligentes", e de meninos "agitados, malandros, dispersivos, indisciplinados, mas inteligentes". Já Valerie Walkerdine, ${ }^{14}$ a partir de investigação desenvolvida na Inglaterra, comenta a discrepância na avaliação dos docentes diante de meninos e meninas, cujos comportamentos "não são lidos de uma forma equivalente": enquanto o bom desempenho escolar das meninas era atribuído ao seu esforço, o desempenho inferior dos garotos era percebido como nãorealização de um potencial brilhante devido a seu comportamento ativo, lúdico. Rob e Pam Gilbert, ${ }^{15}$ autores australianos, referem-se a diversos outros estudos que sustentam esses achados, indicando que professores e professoras freqüentemente preferem ensinar aos meninos, que são considerados como mais interessantes e mais inteligentes. Da mesma forma, em pesquisa recente conduzida em escolas inglesas, Molly Warrington e Michel Younger ${ }^{16}$ descrevem professores/as que, apesar de elogiarem as meninas por sua responsabilidade e compromisso, preferem os garotos, além de estarem dispostos a gastar

${ }^{13}$ SILVA, 2000, p. 215-217.

${ }^{14}$ WALKERDINE, 1995, p. 217.

${ }^{15}$ GILBERT Rob e GILBERT Pam, 1998, p. 207.

${ }^{16}$ WARRINGTON e YOUNGER, 2000, p. 505. 
mais tempo com eles, por considerá-los mais estimulantes, mais vivos na discussão, e mais originais, com opinião própria.

\section{Fru-fru, babadinho e flores no caderno}

O caso extremo da realização daquele tipo de feminilidade silenciosa parecia ser o de Ana. Situada na ponta oposta de Marieta e Alice, em termos de desempenho acadêmico, Ana era a única menina com conceitos "NS" desde o primeiro trimestre, e acabou sendo a única criança reprovada ao final do ano, nas duas furmas de quarta série. Certos traços de uma feminilidade dócil e estereotipada eram insistentemente lembrados nas descrições de Ana feitas pelas professoras:

Ana, também assim, tem um caderno impecável. Você pega o material dela é im-pe-cá-vel, tudo bonitinho, rosinha, vermelhinho, azulzinho, tudo cheio de fru-fru, florzinha no caderno e tal. É daquelas assim, que passa a aula inteira de cabeça baixa. Quando você vai ver o quê que está fazendo, não está fazendo nada do que tem de ser feito... Ela é uma ótima escriba, o que tem que copiar ela copia rapidinho, mas na hora de pensar ela tem muita dificuldade... E é uma criança que vem nas aulas de oficina, tem uma freqüência boa na escola, raramente falta. Mas ela tem muita dificuldade (Célia, ênfase na fala).

A Ana é assim, as canetas cor de rosa, os cadernos da Barbie... [Mas é a única menina com as canetinhas e o caderno da Barbie?] Ah, cor-de-rosinha? Não, cor-de-rosinha quase todas, canetinha colorida no caderno quase todas. [ri] [Você acha que ela é mais do que as outras?] Mais. Mais embonecada. Mais coisinha, mais bichinho, mais caneta... mais embonecadinha [gesto de babadinhos no pescoço] (Laís).

Com menor ênfase, os mesmos traços aparecem na descrição de Marisa, outra menina que esteve nas oficinas de reforço:

Uma das alunas que ficou comigo do começo do ano até o mês passado na oficina, é uma aluna assim: quietíssima, que não tem problema nenhum de indisciplina, que não conversa fora de hora, e que [tem] um caderno super bonitinho, bem caprichado, uma coisa maravilhosa. À primeira vista, perfeito. Mas ela tinha muita dificuldade na produção de texto, precisava estar dando uma força nisso (Laís).

Vivenciando intensamente uma feminilidade assentada na obediência às normas, na organização e na submissão, essas meninas falhavam, do ponto de vista das professoras, por não terem criatividade, voz própria, autonomia e, portanto, participarem pouco, não serem questionadoras, não terem papel de liderança no grupo. Nesse caso, uma forte adesão a um padrão de feminilidade diferente daquele evocado pelas professoras em suas avaliações parece comprometer o sucesso escolar dessas meninas.

Walkerdine ${ }^{17}$ nos convida a uma ampla reflexão a partir dessa "carência" de autonomia e independência intelectual tão freqüentemente percebida em pessoas pertencentes a grupos oprimidos: "porque devemos pensar que trabalhar duro e seguir regras são coisas ruins? As garotas são acusadas de não serem grandes pensadoras ou criativas por que não quebram as regras". De maneira contrastante, Madeleine Arnot e colaboradoras, ${ }^{18}$ num exaustivo "estado da arte" da produção britânica sobre gênero e educação, encontraram evidências de que os meninos se adaptariam mais a métodos

${ }^{17}$ WALKERDINE, 1995, p. 216.

${ }^{18}$ ARNOT et al., 1999, p. 28.

ANO 9562 20 SEMESTRE 
de ensino tradicionais, nos quais devem decorar fatos e regras abstratos e sem ambigüidade, obtendo respostas rápidas; enquanto as meninas se sairiam melhor em tarefas com questões abertas, processuais, relacionadas a situações realistas e que "requerem aos alunos pensar por si mesmos". Esses resultados tão díspares parecem indicar a distância entre as opiniões e avaliações das professoras e as preferências e desempenhos efetivos dos alunos.

\section{Outras facetas}

É interessante, contudo, ouvir a explicação da própria Ana para suas dificuldades, conforme ela nos relatou em conversa gravada com um grupo de três crianças com dificuldades escolares:

A gente não é muito bom na escola, né, Daniel? A gente não estuda muito. A gente não estuda na prova. [Mas você não estuda por quê?] Porque não tenho tempo para estudar. [Por quê? O que é que você faz?] É porque de manhã, por sinal, que eu fico dormindo um pouco. Aí depois minha mãe me liga, para eu arrumar a casa. Aí como que eu vou estudar? Dá meiodia e eu ainda estou arrumando a casa, aí meu pai chega para me trazer para escola. A minha casa eu arrumo meu quarto, o quarto da minha mãe, passo pano, lavo louça, faço tudo. [...] Moro com minha mãe, com meu pai, com minha irmã. Só (Ana).

Nenhuma das professoras e orientadoras pedagógicas da escola parecia conhecer esse outro lado da história de Ana, uma menina branca, vivendo numa família nuclear completa, com situação econômica estável. Na família, ela era descrita, segundo as professoras, como "meu anjinho". Embora o trabalho doméstico não possa ser tomado, de maneira abstrata, como explicação ampla e linear para as dificuldades escolares de alunas, ${ }^{19}$ no contexto específico de Ana ele parece indicar uma certa posição da menina no interior da família, inteiramente coerente com os estereótipos que ela reproduzia na sala de aula, com seu silêncio, sua submissão, sua conformidade às regras, ser uma "boa copista e nada mais".

Outra faceta de Ana, contudo, apareceu também na entrevista com o grupo de alunos, quando ela relatou que havia brigado no recreio e protestou contra os boatos que circulavam a respeito de sua eventual reprovação ao final do ano:

Eu peguei ela, na briga que teve na hora do recreio. Por que ela fica xingando a gente de metida. [...] Aí um dia eu peguei, peguei ela por aqui [gesto] e falei: "olha, menina, você está pensando que a gente é o quê? E você?" E também não gostei de ontem lá, do boato que teve na escola (Ana).

Assim, parece que a submissão e o silêncio de Ana tinham endereço certo - as professoras e a família - mas não eram absolutos, pois podiam ser rompidos em espaços de maior liberdade como o recreio, e diante de seus pares, indicando a possibilidade de ela vir a expressar essa voz, assertividade e autonomia também no processo de aprendizagem escolar. Isso, entretanto, implicaria em alterações na maneira como Ana parecia expressar sua feminilidade e nos padrões das professoras sobre o comportamento adequado às "boas alunas", questões que pareciam totalmente opacas para os adultos da escola.

\footnotetext{
${ }^{19}$ Essa crítica é apresentada, por exemplo, em ROSEMBERG, 2001.
} 


\section{Corpo de mulher, sombra verde e minissaia}

Outros comportamentos ligados à manifestação mais explícita de aspectos da feminilidade também eram, aos olhos das professoras, pouco propícios ao sucesso escolar:

Elas estão muito mais numa fase de paquera, de descobrir: 'eu gosto de fulano', gostar do mesmo menino e... até essa coisa do fuxico, essa coisa pequena do fuxico que tem muito nessa idade, que a gente morre falando com elas... Tem aquelas patricinhas que sempre estão todas arrumadinhas, batonzinho. [...] Elas também têm cadernos impecáveis, mas a coisa vai muito mais do lado sedutor, daquela coisa sensual, do sorrisinho, do mexer cabelo... Nossa! Cabelo (Célia).

Por causa dessas descobertas sentimentais, atribuídas pelas professoras a um amadurecimento fisiológico que seria característico da pré-adolescência, algumas meninas até então bem-sucedidas estariam "caindo de rendimento", ficando distraídas, não concluindo tarefas, deixando de prestar atenção à aula para falar sobre namorados, trocar bilhetinhos, ou porque teriam ficado pensando, pois "estão apaixonadas". Observações nas classes indicaram, efetivamente, o envolvimento de grande parte das crianças de ambos os sexos em conversas sobre namoro, com troca de bilhetes, intrigas, idas e vindas das carteiras e até das salas de aula, além de grande interesse por temas ligados à sexualidade e à intimidade amorosa (procura por livros, conversas, perguntas às professoras e pesquisadoras etc.).

Para algumas meninas, segundo as professoras, esse despertar da sexualidade, com a incorporação de uma série de características de uma feminilidade sedutora, estaria atrapalhando o desempenho escolar, mas elas, chamadas a conversar, estariam procurando formas de conciliar as novas preocupações com suas tarefas escolares. Diante dessas meninas mais erotizadas, atitudes como as de Ana eram qualificadas pelas professoras como "infantis": "a Ana é mais infantil. É engraçado, porque a gente vê Ana andando com crianças da segunda, crianças da terceira [série]. Ela não se mistura muito" (Laís).

Assim, a adesão a padrões de feminilidade mais explícitos ou acentuados tendia a ser avaliada como negativa diante do desempenho escolar das meninas, sejam esses padrões associados à submissão e ao silêncio, sejam à erotização e à sedução. Alícia, por exemplo, foi descrita por Célia como "excelente aluna, responde superbem às coisas da escola", mas, tendo se envolvido numa briga perpassada de conotações sexuais com um colega, era apresentada como "muito bonita, corpo já de mulher e se veste toda ... [gesto de sensualidade], com sombra verde nos olhos, minissaia". Comentando o caso no conselho de classe, Laís insistia na qualificação da menina como provocante e sensual, adjetivos que tomavam sentido pejorativo em sua fala.

Barrie Thorne, etnógrafa norte-americana, descreve situações muito semelhantes em escolas de seu país, onde ela observou meninas de até nove anos, já com seu desenvolvimento físico quase completo, serem tratadas pelos educadores como "desviantes e até mesmo corrompidas ou viciosas". ${ }^{20}$ Thorne chama a atenção para a dificuldade de nossa cultura, e em particular do sistema escolar, fundamentado na classificação etária, em lidar com a sexualidade infantil e com as diferenças individuais nos ritmos de desenvolvimento.

${ }^{20}$ THORNE, 1997, p. 141.

ANO 9564 20 SEMESTRE 
Talvez possamos afirmar que o padrão de feminilidade mais valorizado pelas professoras na avaliação de suas alunas era próximo daquele dominante entre os setores médios intelectualizados, uma feminilidade que rejeita a afirmação exacerbada das diferenças de gênero e propõe um padrão de mulher mais independente que submissa e mais assertiva que sensual. Nem sempre as alunas, porém, partilhavam dos mesmos referenciais.

\section{Diferentes apatias}

Apesar de 13 crianças terem sido indicadas para as oficinas de reforço ao longo do ano, apenas quatro tinham conceitos "NS" em seus boletins: Ana, Mateus T., Mateus C. e Daniel. Segundo ambas as professoras, a principal característica desses quatro alunos era a apatia: "E o que eu sinto é isso, essa apatia e essa questão assim, parece que independente do que eu faça, eu não atinjo" (Laís).

No caso dos meninos, contudo, eles eram também acusados de serem desligados, esquecidos ("Parece que vive em outro mundo", Célia); faltarem muito, inclusive nas oficinas de reforço, não mostrarem "compromisso com a escola"; não perguntarem, não questionarem e não reagirem às admoestações e incentivos das educadoras ("Mesmo se dá uma bronca nele assim, ele parece que tanto faz como tanto fez", Célia ); serem desleixados com seu material escolar, desorganizados, e até mesmo pouco limpos ("Enfim, ele não tem... até aquela coisa da limpeza, sabe? Limpeza de caderno, limpeza de material, limpeza de mochila", Célia). Estas características são evidentemente opostas àquelas encontradas nas meninas com dificuldades, todas assíduas, organizadas, obedientes, comprometidas.

Parecem ser, portanto, "apatias" de naturezas diversas, intrinsecamente articuladas a certas características da feminilidade e da masculinidade: uma apatia decorrente do excesso de submissão e obediência; e outra, de desleixo, descompromisso e desinteresse. Nesse sentido, a postura dos meninos com dificuldades de aprendizagem diante da escola era percebida como mais rebelde e mais assertiva.

Os cadernos das crianças eram um elemento que, na avaliação que as professoras faziam de seus alunos, simbolizava de forma bastante intensa essas diferenças de gênero, verdadeira materialização de uma simbologia de masculinidade e feminilidade. Como ficou evidente nas citações acima em que falavam sobre Ana, tanto Célia quanto Laís comentaram bastante os cadernos e os materiais das crianças, considerados como parte daquilo que devia ser observado para compor o conceito atribuído ao aluno ou aluna:

Ele falta bastante, ele é uma criança muito desligada, ele não se liga muito, esquece muitas coisas, esquece... o caderno dele é bem desorganizado. Ele não tem muito aquela coisa espacial do caderno (...) e é bem complicado.

Ele é uma criança que falta bastante, bastante, não tem assim o mínimo comprometimento com a escola, de perder caderno... de Matemática ele nunca perdeu nada, de Português já no primeiro mês de aula, ele perdeu tanto de Português quanto de História e Geografia. Conseguiu perder os dois cadernos!

Os cadernos dele são completamente bagunçados, uma coisa começa aqui e termina lá... Enfim, ele não tem... até aquela coisa da limpeza, sabe? Limpeza de caderno, limpeza de material, limpeza de mochila... A gente sente que isso não está bem resolvido para ele.

De forma autocrítica, Laís contou como se percebeu seduzida pela forma feminina de organizar os cadernos, que ela classificava como "cadernos cor-de-rosa": 
Inclusive, eu comecei a dar uma incentivada na história dos cadernos cor-de-rosa, fui me pegar depois. É incrível como visualmente você acaba se encantando, aquela letrinha redondinha, aquela coisinha bem organizada e tudo. [...] Então, quando comecei a olhar o caderno, o primeiro mês que eu olhei caderno eu me vi tentada a gostar mais das florzinhas, dos caderninhos cor-de-rosa. Aí eu comecei a me policiar, no ponto de assim: o que é que eu quero do caderno, como professora? Uma determinada organização que dê para ler e que o caderno esteja completo. Isso, sem cobrar cor-de-rosa, florzinha (Laís)

Laís reconhecia fazer uma associação entre feminilidade e cadernos bonitos, enfeitados e bem organizados, mas enfatizava a existência de meninas com cadernos fora desse padrão:

Tem assim meninas com letras maravilhosas e meninas excelentes, alunas com letras esgarçadas e uns cadernos sem os "cor de rosa". Tem excelentes alunas que o caderno, se você olhar, você acha com cara de caderno de menino. Com aquela carona de caderno de menino (Laís, ênfase na fala).

Ao mesmo tempo, apontava o caso isolado de um aluno cujo caderno tinha sido até mesmo confundido com "caderno de menina", quando o levou para casa para corrigir.

Essa professora declarou estar se esforçando para romper com um estereótipo feminino na avaliação dos cadernos, que parece bastante difundido em nossa cultura escolar, mas ao mesmo tempo sentia-se ainda pouco segura quanto aos novos critérios de julgamento:

Me policio muito com isso, porque a tendência em amar esses cadernos cor-de-rosa é muito grande. É grande, sim, não vou te negar. Quando você vê, você acaba pegando um desses como referencial, para mostrar para alguém. Se vocês [pesquisadoras] tivessem falado "traz um caderno para eu ver", talvez eu estivesse com um desses de adesivo debaixo do braço (Laís).

Entre os próprios meninos, Laís avaliava que existia algum preconceito contra caprichar nos cadernos: "há os cadernos desleixados, 'ah, não sei quê', como quem diz: 'florzinha é para menina, não vou caprichar no meu'. Existe isso. Existe esse mito." Mas os bons alunos seriam exatamente aqueles capazes de "se impor", na expressão da professora, e ao mesmo tempo produzir cadernos organizados e caprichados. Sem dúvida, há aqui toda uma questão a ser investigada na sociabilidade entre os próprios garotos, a fim de avaliar em que medida as pressões entre pares, a partir de certos referenciais de masculinidade e de heterossexualidade, interferem no comportamento dos meninos diante da escola e das tarefas e, por conseqüência, também em seu desempenho escolar. ${ }^{21}$

Do ponto de vista das professoras, os cadernos parecem materializar certas características relativas ao gênero, expressando a feminilidade através de limpeza, organização, cores, capricho, decalques e enfeites, e a masculinidade através de desleixo, desorganização, sujeira. E neste caso o bom desempenho estaria relacionado às características tidas como femininas, independentemente do sexo do dono ou dona do caderno.

\footnotetext{
${ }^{21}$ Este tema tem sido bastante explorado na literatura de língua inglesa. Vejam-se por exemplo: EPSTEIN, 1999; JACKSON, 1999; GILBERT, Rob e GILBERT, Pam, 1998; MAC AN GHAILL, 1995; WHITELAW et al., 2000, p. 87-113.
}

ANO $9566 \quad 2^{\circ}$ SEMESTRE 


\section{Um difícil equilíbrio}

Se parecia, pois, ser complicado para as meninas equilibrar diante das professoras o bom desempenho na escola com características associadas à feminilidade, como a passividade ou a sedução, para os meninos também era complexa a articulação entre ser percebido como másculo e ao mesmo tempo como bom aluno. O caso de Frederico, o menino com "caderno de menina", é um bom exemplo dessa corda bamba:

Eu tenho um aluno, o Frederico, um excelente aluno, que eu olhando o caderno um dia na minha casa, eu abri o caderno e mostrei para minha irmã e falei assim: 'olha o caderno dessa menina, como é caprichado...'. 'Nossa! Caprichosa sua aluna', ela falou. Até brinquei com eles [os alunos], contei essa história, que parecia caderno de menina, brinquei com ele (Laís).

Laís enfatizava o descompasso entre a postura de Frederico em sala de aula e a produção no caderno, pois se tratava de um menino agitado, irreverente, indisciplinado mesmo, como confirmaram as observações em classe. A professora o descreveu como "o tipo do garoto que, se você olhar só a aparência, vai dizer que é péssimo aluno". Efetivamente, em sala de aula, ele falava o tempo todo, mexia com os colegas, levantava, circulava, saía e entrava, permanecendo longos períodos fora da sala de aula e, ao voltar, sempre procurava formas de chamar a atenção (ruídos com os pés, assovio, tapinhas nas costas de um e outro etc.). Seu comportamento não parecia, contudo, incomodar nem a professora, nem seus colegas, que recebiam de bom grado suas brincadeiras. Durante as observações, Laís chegou a procurar a pesquisadora à parte, apontando Frederico, para dizer que era ele o portador do "caderno primoroso", um bom aluno no que tangia à aprendizagem, apesar do comportamento dispersivo.

Frederico, Cláudio e mais uns poucos meninos, a maioria classificados pelas professoras como brancos e, de acordo com os dados disponíveis, pertencentes a famílias de setores médios, conseguiam equilibrar na avaliação das professoras um bom desempenho escolar com a dose adequada de masculinidade, expressa através de um certo distanciamento crítico, uma adesão ambígua e não submissa à instituição escolar e suas regras, uma pitada de desafio e bom humor, mantendo certa autonomia e voz própria.

Talvez eles estivessem entre aqueles que, de acordo com os Gilbert, ${ }^{22}$ são meninos que aprenderam como desempenhar (perform, no original) uma versão bem-sucedida de masculinidade dentro da sala de aula, ganhando assim tanto o reconhecimento de seus professores quanto o respeito de seus colegas. São garotos que desenvolvem a habilidade de equilibrar-se entre o mundo do pátio de recreio e da cultura dos meninos e o mundo da sala de aula, descobrindo ou inventando uma posição masculina bemsucedida em meio a essa tensão.

Em nossa escola, porém, quando essa dose de masculinidade era percebida como exagerada, ou como excessivamente agressiva, passava a ser qualificada pelas professoras como "desleixo, desinteresse e apatia", no caso dos meninos com conceito "NS", ou como "indisciplina e agressividade", que predominavam no julgamento daqueles que, apesar de um desempenho "mediano em sala de aula", tinham constantes problemas disciplinares. Um dos garotos que participavam do reforço, André, expressou muito claramente esse difícil equilíbrio, ao comentar o comportamento dos "bons alunos" de sua classe: "Eles zoam, mas eles prestam atenção e conseguem fazer...".

${ }^{22}$ GILBERT, Rob e GILBERT, Pam, 1998, p. 207.

ESTUDOS FEMINISTAS $567 \quad 2 / 2001$ 
André parecia antes de mais nada perplexo ante essa capacidade demonstrada por alguns de seus colegas. Por que a escola considerava que alguns meninos erravam na dose? Por que era mais difícil para uns que para outros construir um padrão de masculinidade percebido pelas professoras como compatível com o sucesso acadêmico?

\section{Diferentes bagunças}

As masculinidades e suas características pareciam mais opacas e ainda menos questionadas na escola que as feminilidades. As falas das professoras não relacionavam a agressividade e indisciplina, que nossa cultura associa à masculinidade, com as dificuldades escolares dos meninos, ao contrário do que faziam ao comentar as meninas com problemas de aprendizagem, realçando nelas características marcadas por traços de feminilidade (submissão ou erotização). Além disso, Laís e Célia pareciam, num primeiro Olhar, distinguir comportamentos disruptivos e aproveitamento escolar.

Durante as entrevistas e a observação no conselho de classe, elas diferenciaram com bastante ênfase os alunos que tinham conceito "NS" ("apáticos") dos alunos indisciplinados. Afirmavam que os problemas de agressividade e indisciplina eram da classe toda, "uma classe atípica desde a primeira série" (Laís), e que os meninos que vinham tendo sucessivos problemas com a orientação pedagógica devido a brigas e indisciplina no recreio e nas aulas de artes e educação física (conteúdos a cargo de professores especialistas) não tinham problemas sérios de aprendizagem com elas, em Português e Matemática.

Não são maravilhosos mas não são dos piores, não, é bem mediano. [...] Porque foi aquilo que eu te falei, na classe, na aula, na hora de trabalhar, na hora de a gente trabalhar Matemática, na hora de trabalhar Português, na hora de trabalhar essas coisas assim, na classe, esses comportamentos fora do normal, que apareceu no Conselho, isso não aparece para a gente (Célia).

Os problemas - agressão física e verbal entre colegas, principalmente - surgiriam sempre no recreio e nas aulas ministradas por outros professores, com quem as classes não teriam um vínculo estabelecido, nem uma relação clara de autoridade e respeito aos limites. Na percepção de Célia e Laís, se sentiam a ausência de limites muito bem delimitados e sempre relembrados, todos os alunos e alunas das quartas séries acabavam "se envolvendo em confusão":

Se você deixa muito solto, a coisa assim, todos eles fazem bagunça. Entra menina, entra menino, entra a menininha que sempre sabe tudo, que sempre..., aquela assim que você diz: "essa daí é perfeitinha, ela faz lição de casa, participa, questiona". Mas se deixa muito aberto, até ela entra na bagunça, vira zona geral. [...] De modo geral, deixou um pouquinho mais livre, deu uma brechinha, eles perceberam, acham que dá para fazer uma zoninha, eles já usam e abusam (Célia).

Assim, o bom desempenho escolar só estaria muito frouxamente articulado ao comportamento disciplinado e não poderíamos explicar por esse caminho os problemas escolares dos meninos. A indisciplina atrapalharia o desempenho das classes como um todo, em certos momentos e em certas aulas em particular, mas não seria a marca para avaliar negativa ou positivamente esse ou aquele aluno.

Não é só ele que vai atrapalhar, vai atrapalhar todo um contexto, todo ... todo mundo que está em volta. Você está fazendo um trabalho de Matemática, que você precisa de concentração, você precisa pensar, se tem dois ali se matando, é impossível [risos] (Célia).

ANO $9 \quad 568$ 20 SEMESTRE 
Por outro lado, para elas, a indisciplina também não seria marca exclusiva das crianças do sexo masculino, não estaria diretamente relacionada a características de gênero: "Também temos nomes de meninas, com esse mesmo comportamento, menos vezes, mas acontece" (Laís). Elas enfatizaram, tanto nas entrevistas como nos conselhos de classe, a existência de "meninas agressivas", "brigonas" e indisciplinadas:

Nessa sala, a gente tem muita menina que se mete em confusão, a gente tem muita menina que tem conceitos bons, com atitudes boas em relação à escola mas que também se metem em confusão. Confusão do tipo de bater, de brigar, de bater boca (Célia).

As meninas que apresentavam comportamentos tidos como não-femininos eram mesmo postas em destaque, com um misto de orgulho e vergonha, elogio e recriminação. Célia, por exemplo, comentou que, diferentemente de quando era jovem, via meninas jogando futebol e de igual para igual com os garotos.

A Keila joga bem, joga assim feito eles... Joga no time deles e assim, dando ponta-pé, sabe aquele jeito todo assim?... Ela joga estilo eles. Ela joga e eles disputam para ter ela no time. Andréa também é uma que joga futebol. Tem outras que são mais Patricinhas e tal, mas tem uma e outra que gosta (Célia).

A julgar por essas falas, nem a indisciplina nem a agressividade (expressa em brigas entre pares) seriam marcadas pelas relações de gênero. Ao contrário, estariam igualmente distribuídas entre meninas e meninos. Uma tal situação contrariaria muitas das explicações correntes sobre o fracasso escolar dos meninos, freqüentemente associado a problemas de comportamento indisciplinado. Muitos estudos relatam a associação feita pelas professoras e professores entre a indisciplina dos meninos e seu baixo desempenho acadêmico, questionando então as diferentes percepções dos educadores/as sobre as crianças de cada sexo e suas decisões sobre quem precisa de reforço e atenção especial. ${ }^{23}$

Uma pesquisa norte-americana, ${ }^{24}$ por exemplo, mostrou que naquele país os meninos são muito mais freqüentemente indicados para as classes especiais, onde se colocam aqueles que teriam problemas psicológicos - de aprendizagem ou emocionais. Os dados indicaram que, quanto mais subjetivo é o diagnóstico de um certo problema ("distúrbios emocionais", por exemplo), maior é a presença masculina. Assim, "em lugar de identificar os problemas de aprendizagem, o pessoal escolar poderia estar classificando incorretamente problemas de conduta.". Isto é, as meninas, caladas, obedientes e bem comportadas seriam mais facilmente ignoradas, enquanto os meninos, rebeldes e incômodos, seriam prováveis candidatos à educação especial, ou, no caso brasileiro, às classes de aceleração e atividades de reforço.

Estariam nossas professoras conseguindo separar os "problemas de conduta" das dificuldades de aprendizagem e avaliando o desempenho acadêmico de alunos e alunas objetivamente? Se considerarmos apenas as crianças classificadas como "NS", diríamos que sim. Mas, tomando o conjunto dos alunos que foram indicados para atividades de reforço, veremos que era composto por dois tipos diferentes de meninos: aqueles três com conceitos "NS", classificados pelas professoras como "apáticos", e mais seis garotos, quatro dos quais haviam recebido pelo menos uma advertência ou suspensão no ano de 2000 , todas elas relacionadas à agressão física contra colegas. ${ }^{25}$

${ }^{23}$ GILBERT, Rob e GILBERT, Pam, 1998; SILVA, 1999; WALKERDINE, 1995.

${ }^{24}$ WELLESLEY, 1992, p.14.

${ }^{25} \mathrm{Um}$ dos demais veio a receber punição formal nos primeiros meses de 2001.

ESTUDOS FEMINISTAS 569 2/2001 
Ao todo, seis meninos e apenas uma menina da quarta série receberam advertências e/ou suspensões em 2000, sendo seis crianças percebidas como negras (pretas e pardas) e apenas um garoto branco (classificação das professoras). Cinco deles provinham de famílias com renda mensal inferior a dez salários mínimos e um não informou. Destaque-se novamente que, entre estes sete, quatro estavam nas oficinas de reforço.

Mesmo considerando que naquela escola punições formalizadas como essas referiam-se a casos extremos, e eram adotadas após diversas admoestações e chamadas à orientação que não eram registradas, parece que o esforço para realçar a existência de "meninas agressivas" e indisciplinadas e a visibilidade que sua presença minoritária ganhava nas falas eram um artifício que cumpria a função de desassociar masculinidade de agressividade e violência, permitindo a percepção desses comportamentos como neutros do ponto de vista de gênero. Mereceria uma discussão à parte a presença quase absoluta, nesse grupo dos alunos com problemas disciplinares formalizados, de crianças vindas de famílias de menor poder aquisitivo e percebidas como negras pelas professoras. Entrevistando jovens desempregados que haviam saído recentemente do sistema escolar australiano, após uma trajetória de fracasso, Robert Connell ${ }^{26}$ indica como diferentes masculinidades vão sendo construídas em relação à diferenciação hierarquizada em que a escola aloca os estudantes, através da constante competição e classificação. À medida que se reconhecem como fracassados na escola, vendo fecharem-se as possibilidades de realizar um certo padrão de masculinidade hegemônica e de controlar um certo tipo de poder social ligado ao sucesso acadêmico e às profissões liberais, alguns jovens, principalmente oriundos das classes trabalhadoras, podem reagir buscando "outras fontes de poder, até mesmo outras definições de masculinidade", muitas vezes simbolizadas na força física, na agressão e nas conquistas heterossexuais.

Alguns de nossos alunos da quarta série talvez estivessem dando os passos iniciais numa trajetória desse tipo. Não apenas eles possivelmente traziam de casa referenciais de masculinidade diferentes dos valorizados pelas professoras ao avaliarem os alunos, um padrão mais assentado na força, na agressividade e na heterossexualidade, com diferenças de gênero mais acentuadas, de forma paralela a alguns dos padrões de feminilidade percebidos pelas professoras nas meninas. Além disso, a própria escola, ao empurrá-los para o fracasso acadêmico, poderia estar contribuindo para que eles assumissem essas formas de masculinidade como única via de realização de algum poder e autonomia, já que a masculinidade está organizada, em escala macro, em torno da posse do poder social. Eles estariam lidando com as múltiplas incertezas de sua posição, desenvolvendo o que era considerado pelos adultos da escola como agressividade, abuso de poder e mesmo violência. ${ }^{27}$ Ao deixar intocada a discussão sobre a relação intrínseca e pretensamente natural entre masculinidade e poder e ao mesmo tempo dificultar o acesso a outras formas de poder socialmente mais aceitáveis, como através do reconhecimento acadêmico, a escola pode estar contribuindo na construção de trajetórias de violência. Os problemas crescentes de indisciplina, agressividade física e verbal, formação de gangue e pequenos furtos, que a escola estudada registrava em relação a uma parte desses meninos em 2001, quando já eram alunos da quinta série, parecem apontar nessa direção. ${ }^{28}$

${ }^{26}$ CONNELL, 1998, p. 145.

${ }^{27}$ Ver também ARNOT et al., 1999, p. 144.

${ }^{28}$ Não se pode, porém, fazer qualquer correlação linear das práticas de violência na escola com o fracasso escolar, o padrão sócio-econômico das famílias ou a raça/etnia da criança. Ver, a respeito: GILBERT, Rob e GILBERT, Pam, 1998, p. 187; SEWELL, 1999.

ANO $9 \quad 570$ 20 SEMESTRE 
Por outro lado, as observações em classe confirmaram a presença de meninas conversando, saindo da classe, trocando bilhetes, fazendo algumas "bagunças", mas sempre mais discretas e de menor duração temporal que as desordens dos meninos. Nara Bernardes $^{29}$ já observara esse tipo de situação em sua tese de doutorado, mostrando como a indisciplina das meninas era de natureza diferente daquela dos meninos, ligada mais a conversas e a ações discretas, pouco percebidas pelas professoras, enquanto os garotos se moviam mais, falavam alto e enfrentavam mais abertamente os adultos, sendo, portanto, mais freqüentemente percebidos como indisciplinados.

A esse respeito, as falas das crianças foram bastante reveladoras, pondo a descoberto a arte das meninas em conciliar diversão e estudo, e driblar muito melhor a vigilância e as punições das educadoras, através de uma postura menos desafiadora:

Eu acho que as meninas são mais espertas do que os meninos. [...] Eles não prestam atenção, eles ficam conversando, fica mascando chiclete na aula das professoras. [E as meninas?] As meninas também desenham, elas não prestam atenção. É a mesma coisa, elas conversam, a professora chama a atenção delas e elas prestam atenção. [E se a professora chama a atenção dos meninos, eles ficam quietos?] Não, não ficam... Aí quando ela vira, eles continuam conversando. Aí quando a professora pede para parar, as meninas param (André).

Efetivamente, a discrição - com suas conseqüências positivas ou negativas - parecia ser uma característica das garotas da quarta série: ao todo, 36 dos 60 alunos de ambos os sexos da quarta série foram nomeados explicitamente durante nossa pesquisa, considerando-se aqueles punidos formalmente nos prontuários da escola, os indicados para as oficinas de reforço ou ainda os que foram mencionados espontaneamente pelas professoras em suas entrevistas, seja com elogios e críticas, seja em casos. Desses 36 alunos com algum tipo de destaque - positivo ou negativo - 23 eram do sexo masculino e 17 do feminino. Se considerarmos que eram apenas 25 meninos, veremos que somente dois não foram mencionados, enquanto das 35 meninas 18 permaneceram na sombra, como que invisíveis. ${ }^{30}$

\section{Uma gramática da avaliação escolar}

Para as crianças ouvidas, o que caracterizava um bom aluno era antes seu comportamento que suas notas. Ele "faz todas as lições, não responde para a professora e faz tudo que ela quer" (André). Só secundariamente eles mencionaram "estudar para a prova" e "tirar nota boa" (Ana) como critérios. Na percepção deles, a prática de avaliação das professoras estava baseada tanto no comportamento quanto no desempenho propriamente acadêmico, o que não correspondia à percepção que elas mesmas tinham de seus critérios avaliativos. Pois, nas falas das professoras, alunos e alunas que "fazem tudo o que a professora quer" não seriam avaliados como excelentes e haveria uma relação muito tênue entre atitudes e desempenho acadêmico.

E se a questão da indisciplina influencia ou não o desempenho, não sei se isso é muito claro. Que a indisciplina influencie, acredito que influencia. Os três que tiveram problemas agora com a orientação [pedagógica] têm algumas dificuldades, mas estão com S. E, por incrível que pareça, os três que estão com NS, eu não tenho tido problema nenhum de indisciplina com nenhum dos três (Laís).

29 BERNARDES, 1989 , p. 162-165.

${ }^{30} \mathrm{O}$ fato de o tema central das entrevistas com as professoras ser o fracasso escolar dos meninos poderia ser considerado como fonte de distorção nesses números. Porém, nessas falas foram mencionadas mais meninas (12) que meninos (9). 
Nossas observações indicaram que os alunos tinham alguma razão ao enfatizarem a necessidade de ser percebido como aluno de bom comportamento para ser bem avaliado, como tem sido insistentemente apontado na literatura. Não apenas o grupo de alunos indicados para reforço se superpunha em parte à lista de crianças que sofreram algum tipo de punição formal por problemas disciplinares, como também, no último conselho de classe do ano, assistimos à indicação do aluno Washington, que durante toda a quarta série estivera fora da recuperação, para a oficina de reforço do ano seguinte, com uma justificativa que se centrava muito mais em seu comportamento durante a viagem de formatura realizada há pouco, do que em problemas de aprendizagem: "Além de indicar para o reforço em Português e Matemática, queremos fazer uma ressalva sobre $\circ$ comportamento dele. É preciso ter muito cuidado e estar muito atento às atitudes do Washington" (Laís).

Na verdade, ao apresentarem em entrevistas seus critérios de avaliação, ambas as professoras haviam afirmado considerar tanto a aprendizagem quanto o que chamavam de "compromisso da criança com o cotidiano da escola", e era através da avaliação desse compromisso que eram considerados elementos ligados às atitudes e comportamentos de forma tão decisiva quanto o desempenho mais estritamente acadêmico. Avaliar esses comportamentos, porém, era uma tarefa extremamente subjetiva, mesmo numa escola razoavelmente estruturada e com espaços coletivos de discussão como aquela. Para fazê-lo, as professoras tinham que lançar mão de repertórios e referenciais pessoais, apenas relativamente conscientes, sem perceber integralmente seu caráter arbitrário, sem escolhê-los e controlá-los inteiramente.

Seguindo Phillippe Perrenoud, ${ }^{31}$ seria útil lançar mão aqui do conceito de habitus, como formulado por Bourdieu: "uma gramática geradora das práticas", em nosso caso, práticas avaliativas. No complexo processo que é a relação pedagógica, a racionalidade seria apenas ilusória, sendo inevitável "uma erupção de valores, de subjetividade, afetividade" e um certo grau de dependência diante de interesses e preconceitos. $O$ professor enfrentaria as diferentes situações de seu cotidiano profissional, entre elas a avaliação dos alunos, "a partir do conjunto de esquemas mais ou menos conscientes de que dispõe, esquemas de ação mas também de percepção, de avaliação, de pensamento". ${ }^{32}$

Nesse repertório de valores, as idéias e os símbolos socialmente construídos de masculinidade e feminilidade estariam presentes, tanto quanto outras hierarquias ligadas à estrutura sócio-econômica, às raças ou etnias etc. Se já são ativas e marcantes em sistemas de avaliação escolar mais formalizados, ligados à realização de testes, à atribuição de notas e à organização da escola em séries, essas hierarquias parecem tornar-se ainda mais poderosas nas chamadas "avaliações de processo", associadas aos sistemas de ciclos e não-repetência, particularmente pela subjetividade e indefinição de critérios que costumam cercar a adoção desse tipo de mudança, em curso em muitas escolas brasileiras. Mais do que em qualquer outro momento, pensar os processos de avaliação dos alunos no sistema escolar brasileiro requer hoje refletir sobre as relações sociais de gênero, masculinidades e feminilidades que informam nossas concepções de bom aluno, aprendizagem, disciplina, infância, ao lado de outras hierarquias mais ou menos consagradas nessa reflexão, como as de classe social e etnia.

${ }^{31}$ PERRENOUD, 1993, p. 24.

${ }^{32}$ PERRENOUD, 1993, p. 38.

ANO 9572 20 SEMESTRE 


\section{Referências bibliográficas}

ABRAMOWICZ, Anete. A menina repetente. Campinas: Papirus, 1995.

AQUINO, Julio Groppa (Org.). Erro e fracasso na escola: alternativas teóricas e metodológicas. São Paulo: Summus, 1992.

ARNOT, Madeleine et al. Closing the Gender Gap: Postwar Education and Social Change. Cambridge: Polity Press, 1999.

ARROYO, Miguel. Fracasso/sucesso: um pesadelo que perturba nossos sonhos. Programa de correção de fluxo escolar. Cadernos em Aberto, Brasília: INEP, n. 17, jan. 2000.

BERNARDES, Nara M. G. Crianças oprimidas: autonomia e submissão. 1989. Tese (Doutorado) - Faculdade de Educação da UFRGS, Porto Alegre.

CARVALHO, Marília Pinto de. No coração da sala de aula: gênero e trabalho docente nas séries iniciais. São Paulo, Xamã, 1999.

. Explorando as causas do fracasso escolar de meninos e rapazes. São Paulo, 2000. (Relatório de pesquisa).

CONNELL, Robert W. "Disruptions: Improper Masculinities and Schooling". In: KIMMEL, Michael; MESSNER, Michael (Eds.). Men's Lives. Boston: Allyn and Bacon, 1998.

EPSTEIN, Debbie. "Real Boys don't Work: Underachievement, Masculinity, and the Harassment of sissies". In: EPSTEIN, Debbie et al. (Eds.). Failing Boys? Issues in Gender and Achievement. Buckingham: Open university Press, 1999.

GILBERT, Rob; GILBERT, Pam. Masculinity Goes to School. London: Routledge, 1998.

JACKSON, David. "Breaking Out of the Binary Trap: Boys' Underachievement, Schooling and Gender Relations". In: EPSTEIN, Debbie et al. (Eds.). Failing Boys? Issues in Gender and Achievement. Buckingham: Open university Press, 1999.

MAC an GHAILL, Máirtín. The Making of Men: Masculinities, Sexualities and Schooling. Buckingham: Open University Press, 1995.

PATTO, Maria Helena Souza. A produção do fracasso escolar: histórias de submissão e resistência. São Paulo: T.A.Queiroz, 1990.

PERRENOUD, Philippe. Práticas pedagógicas, profissão docente e formação: perspectivas sociológicas. Lisboa: Dom Quixote/Instituto de Inovação Educacional, 1993.

ROSEMBERG, Fúlvia. Educação formal, mulher e relações sociais de sexo/gênero: balanço preliminar. Itu, SP. Seminário Estudos de Gênero Face aos Dilemas da Sociedade Brasileira. Fundação Carlos Chagas/Fundação Ford, 2001 (mimeo).

SILVA, Cármem Duarte et al. Meninas bem-comportadas, boas alunas, meninos inteligentes, mas indisciplinados. Cadernos de Pesquisa, São Paulo, n. 107, p. 207-225, julho 1999.

SEWELL, Tony. "Loose Canons: Exploding the Myth of the Black Macho Lad". In: EPSTEIN, Debbie et al. (Eds.). Failing Boys? Issues in Gender and Achievement. Buckingham: Open university Press, 1999

THORNE, Barrie. Gender Play: Girls and Boys in School. New Brunswich, NJ: Rutgers University Press, 1997.

WALKERDINE, Valerie. O raciocínio em tempos pós-modernos. Educação e Realidade, Porto Alegre, n.20, v.2, p. 207-26, jul. dez. 1995.

WARRINGTON, Molly; YOUNGER, Michael. The Other Side of the Gender Gap. Gender and Education, London, v. 12, n. 4, p. 493-508, 2000.

WELLESLEY College Center for Research on Women. Cómo las escuelas estáfan a las niñas: un estudio de las principales investigaciones en torno a las niñas y la educación. Washington, American Association of University Women, 1992. 
MAU ALUNO, BOA ALUNA?

WHITELAW, Sarah et al. Gender, Behavior and Achievement: a Preliminary Study of Pupil Perceptions and Attitudes. Gender and Education, London, v. 12, n. 1, p. 87-113, 2000. ZAIDMAN, Claude. La mixité à l'école primaire. Paris: L'Harmattan, 1996.

Bad boy, good girl? How teachers evaluate students

Abstract: This article is based on a qualitative research in an elementary school at São Paulo, Brazil, and discusses the academic evaluation of pupils, searching if teacher's opinions about masculinity and femininity affect her/his judgments. The text concludes that it is time to reflect upon these topics in the educational field, because gender inequalities and hierarchies are powerful interferences on the evaluation processes used in most Brazilian elementary schools.

Keywords: gender relations, elementary school, evaluation, school failure.

ANO $9574 \quad 20$ SEMESTRE 